\title{
VARIAÇÃO NA CONCORDÂNCIA NOMINAL DE NÚMERO NA FALA DOS MORADORES DA COSTA DA LAGOA E REGIÃO CENTRAL DA CIDADE DE FLORIANÓPOLIS (SC)
}

\author{
NOMINAL NUMBER AGREEMENT VARIATION IN THE SPEECH OF RESIDENTS \\ OF COSTA DA LAGOA AND CENTRAL REGION OF FLORIANÓPOLIS CITY (SC)
}

\section{Flávia Santos Martins}

Doutoranda em Linguística pelo Programa de Pós-graduação em Linguística da Universidade Federal de Santa Catarina flavinhaingrid@yahoo.com.br

\section{Hilda Leonor C. de Oliveira}

Doutoranda em Linguística pelo Programa de Pós-graduação em Linguística da Universidade Federal de Santa Catarina

hildaleonor@gmail.com

\begin{abstract}
RESUMO: Este artigo tem como objetivo investigar a variação na concordância nominal de número no falar dos moradores de Florianópolis (SC), especificamente da comunidade da Costa da Lagoa e da Região Central (Trindade e Coqueiros). Para realização desta pesquisa foram controlados de forma sistemática os seguintes grupos de fatores: extralinguísticos - a idade, o sexo, a escolaridade e a diazonalidade - e linguísticos - a saliência fônica, a posição, a classe gramatical e o contexto seguinte. Foi analisada a fala de dezesseis informantes, oito da Costa da Lagoa e oito da Região Central. Foram analisados 1.357 dados no programa Goldvarb 2001. Desses dados, o resultado geral da análise evidenciou 1.029 da variante 'presença de marcas formais de plural', correspondendo a $75 \%$ dos dados, e 328 da variante 'ausência de marcas formais de plural', correspondendo a $24 \%$ dos dados. A análise das variáveis independentes evidenciou que o uso da variante 'presença de marcas formais de plural' é condicionado pelos seguintes grupos de fatores, por ordem de seleção estatística: classe gramatical, escolaridade, idade, saliência fônica, diazonalidade e posição. Esperamos com esta pesquisa ter mostrado como é realizada a concordância nominal de número na fala dos florianopolitanos entrevistados, assim como ter evidenciado a partir da análise das variáveis independentes quais delas (linguísticas e extralinguísticas) condicionam o uso da variante 'presença de marcas formais de plural'.
\end{abstract}

PALAVRAS-CHAVE: Sociolinguística. Concordância Nominal de Número. Variação.

ABSTRACT: This article aims to investigate the variation in nominal number agreement in the speech of residents of Florianópolis (SC), specifically from the district of Costa da Lagoat and the central region (Trindade and Coqueiros districts). In order to conduct this research the following groups of independent factors were systematically controlled: extra-linguistic factors - age, gender, educational level and diazonality; linguistic factors - phonic salience, position, grammatical class and ensuing context. We analyzed the speech of sixteen informants, eight of them from Costa da Lagoa and eight from the central region. 1357 data were analyzed with Goldvarb 2001. From these 
data, the overall result of the analysis showed 1029 occurrences of the variant 'presence of formal plural marks', corresponding to $75 \%$ of the data, and 328 occurrences of the variant 'absence of formal plural marks', corresponding to $24 \%$ of the data. As to the results for the independent variables, the following ones seem to condition the use of the variant 'presence of formal plural marks', in order of selection by the program: grammatical class, educational level, age, phonic salience, diazonality, and position. We expect by this research to have shown how agreement in nominal number is produced by the surveyed people from Florianópolis, as well as to have evidenced from the analysis of the independent variables which ones among them (linguistic and extra-linguistic ones) condition the use of the variant 'presence of formal plural marks'.

KEYWORDS: Sociolinguistics. Nominal number agreement. Variation.

\section{INTRODUÇÃO}

Desde a década de 1960, estudos preocupados em observar a língua como um fato social vêm sendo realizados a fim de atestar a variabilidade sistemática que rege os fenômenos linguísticos. No Brasil, por exemplo, existem diversas pesquisas que atestam a variabilidade que constitui a língua portuguesa rompendo, assim, com a ideia de homogeneidade. Isso foi possível a partir da investigação de fenômenos fonéticofonológicos, morfológicos, morfossintáticos, sintáticos, semânticos e discursivos.

Um dos fenômenos que chama atenção no português brasileiro (doravante PB) no nível morfossintático e que vem sendo estudado desde a década de 1970 é a variação existente em sintagmas nominais (doravante SNs) que indicam a ideia de pluralidade: a concordância nominal de número. Segundo várias pesquisas (SCHERRE, 1988; FERNANDES, 1996; CAMPOS e RODRIGUES, 2002, entre outros), o plural no SN pode ser expresso pela presença de marcas formais de plural em todos os elementos flexionáveis ("As meninas bonitas") ou pela ausência de marcas formais de plural em alguns dos elementos flexionáveis ("As meninas bonitaØ”; "As meninaØ bonitaØ”). Trataremos, doravante, a primeira variante como 'presença de marcas formais de plural' e a segunda como 'ausência de marcas formais de plural'.

Neste artigo pretendemos, de maneira geral, investigar esse mesmo fenômeno observando o falar florianopolitano ${ }^{1}$, considerando as localidades Costa da Lagoa e Região Central (Coqueiros e Trindade) através de dois corpora: um da amostra de Monguilhott (2009) e outro da amostra Floripa (2012).

Para isso, especificamente, pretendemos: i) descrever como é realizada a concordância nominal de número na fala dos moradores da Costa da Lagoa e Região Central (Florianópolis-SC) e ii) analisar os grupos de fatores linguísticos e extralinguísticos que podem estar condicionando a variação na concordância nominal de número na fala dos moradores da Costa da Lagoa e da Região Central.

\footnotetext{
1 Esse fenômeno já foi estudado em Florianópolis em 1996 por Fernandes quando investigou algumas cidades do Estado de Santa Catarina em sua dissertação. Essa pesquisadora utilizou para sua investigação o corpus do projeto VARSUL (Variação Linguística da Região Sul do Brasil), coletado na década de 1990.
} 
Analisamos a fala de dezesseis informantes, oito na Costa da Lagoa (considerado um bairro menos urbano) e oito na Região Central (considerada mais urbana), estratificados da seguinte forma: dois homens e duas mulheres com mais de 40 anos de idade e dois homens e duas mulheres com menos de 37 anos de idade, observando dois níveis de escolaridade: ensino fundamental e ensino superior. $O$ Quadro 1 ilustra melhor essa estratificação.

\begin{tabular}{|l|l|l|l|l|}
\hline & \multicolumn{2}{|l|}{ Costa da Lagoa } & \multicolumn{2}{l|}{ Coqueiros e Trindade } \\
\cline { 2 - 5 } & Masculino & Feminino & Masculino & Feminino \\
\hline $\begin{array}{l}\text { Mais de 40 anos } \\
\text { Ensino Fundamental }\end{array}$ & 1 & 1 & 1 & 1 \\
\hline $\begin{array}{l}\text { Mais de 40 anos } \\
\text { Ensino Superior }\end{array}$ & 1 & 1 & 1 & 1 \\
\hline $\begin{array}{l}\text { Menos de 37 anos } \\
\text { Ensino Fundamental }\end{array}$ & 1 & 1 & 1 & 1 \\
\hline $\begin{array}{l}\text { Menos de 37 anos } \\
\text { Ensino Superior }\end{array}$ & 1 & 1 & 1 & 1 \\
\hline
\end{tabular}

Quadro 1- Estratificação social dos informantes entrevistados em Florianópolis (SC)

Para a análise do fenômeno, utilizamos o programa Goldvarb 2001 a partir do controle das seguintes variáveis independentes: quanto aos fatores linguísticos, observamos a posição no sintagma nominal, a classe gramatical, a saliência fônica e o contexto seguinte; e quanto aos fatores extralinguísticos, observamos a idade, a escolaridade, o sexo e a diazonalidade.

Na seleção dos SNs para a transcrição grafemática foram eliminados dados dos seguintes tipos: i) casos de assimilação, como em "as saias", "esses santos de barro", "dos seis anos", "meus pais se separaram", "vinte anos já", "os juízes"; ii) casos em que não conseguíamos perceber se a marca de plural era falada ou não, principalmente em casos em que a pronúncia do $\{-\mathrm{s}\}$ morfêmico com a variante alveopalatal sonora era seguido da consoante [d]: "uns problemas de", "nove anos de babá".

Nas próximas seções apresentaremos os resultados de alguns trabalhos realizados sobre a concordância nominal de número no Brasil, enfatizando apenas aqueles resultados cujas variáveis independentes foram controladas nesta pesquisa. Trataremos também da Teoria da Variação e Mudança e da Dialetologia Pluridimensional, abordagens teórico-metodológicas que adotamos para a análise do fenômeno investigado. E, por fim, discutiremos os resultados encontrados nesta pesquisa.

\section{SOBRE A CONCORDÂNCIA NOMINAL DE NÚMERO}

As pesquisas realizadas no Brasil em relação à concordância nominal de número têm mostrado que se trata de um fenômeno variável, principalmente na fala, já que a 
ideia de plural no SN pode ser indicada por mais de um tipo de construção: i) com todos os elementos flexionáveis totalmente marcados pela presença de marca formal de plural ou ii) parcialmente marcados pela presença de marca formal de plural. Dentre os vários estudos já realizados sobre esse fenômeno à luz da Teoria da Variação e Mudança, apresentaremos aqui alguns resultados de Scherre (1988), de Fernandes (1996), Campos e Rodrigues (2002) e Santos (2010), a fim de observarmos quais grupos de fatores linguísticos e extralinguísticos estão condicionando ou não esse fenômeno.

Scherre (1988), em sua tese de doutoramento, fez uma reanálise ${ }^{2}$ da concordância nominal de número a partir da fala de moradores do Rio de Janeiro. O corpus analisado por ela foi constituído de 64 informantes, o que correspondeu a 64 horas de fala gravada. Essas entrevistas foram feitas em duas etapas: a primeira foi realizada no período de 1982 a 1984 com 48 informantes entre 15 a 71 anos de idade e a segunda no período de 1983 a 1985 com 16 informantes entre 7 a 14 anos. Os informantes da primeira amostra foram estratificados quanto à escolaridade (um a quatro anos; cinco a nove anos e dez a onze anos), quanto ao sexo e quanto à faixa etária (15 a 25 anos, 26 a 49 anos e 50 anos em diante). Os da segunda amostra também foram estratificados quanto à escolaridade (um a quatro anos e cinco a oito anos), quanto ao sexo e a idade (7 a 14 anos). Foram coletados 7.193 SNs das entrevistas. Para a análise dos dados, Scherre (1988) utilizou o programa VARBRUL.

A referida pesquisadora fez a análise da concordância nominal de número sob duas perspectivas: uma atomística, que considera a relação entre os elementos do SN; e outra não atomística, que considera a relação entre os SNs no plano oracional. Para cada tipo de análise controlou determinadas variáveis linguísticas. Como nesta pesquisa trabalhamos apenas com a análise atomística, discutiremos neste artigo apenas as variáveis linguísticas que foram controladas por Scherre (1988) nessa perspectiva, assim como as que foram selecionadas pelo programa estatístico utilizado por essa pesquisadora. Das variáveis controladas, as selecionadas pelo programa computacional VARBRUL, no estudo da autora, foram: marcas precedentes e posição, saliência fônica (dimensões processos e tonicidade), relação dos elementos não nucleares em função do núcleo e posição dos elementos nucleares no $\mathrm{SN}$, formalidade dos substantivos e adjetivos, grau dos substantivos e adjetivos, animacidade dos substantivos, contexto fonético/fonológico seguinte e função resumitiva. As variáveis que não se mostraram significativas foram: número de sílabas dos itens lexicais singulares e processos morfofonológicos de formação de plural.

A seguir apresentaremos sucintamente os resultados estatísticos para cada variável, considerando apenas aqueles dados dos informantes adultos (amostra 1).

Quanto à variável "marcas precedentes e posição"3, Scherre (1988) chegou à conclusão de que a presença de marcas nos dois primeiros elementos do SN leva à presença de marcas no terceiro e quarto elementos $\left(0,68^{4}\right)$, enquanto a ausência de marca a partir do segundo elemento do SN leva à ausência de marcas nos terceiro e quarto elementos $(0,07)$ :

2 Em 1978, Scherre havia analisado esse mesmo fenômeno em sua dissertação de mestrado a partir da fala de dez moradores do Rio de Janeiro.

A correlação entre essas duas variáveis se mostrou mais relevante para a interpretação da variável dependente.

$4 \quad$ Peso relativo. 
1) $\operatorname{aS~meninaS~}$ 2) $_{\text {essas panitaS }}$

Esse resultado, segundo Scherre (1988), evidencia a tendência de formas semelhantes se agruparem, o que ela denomina como o Princípio do Paralelismo.

Quanto à saliência fônica (processos e tonicidade), a pesquisadora chega à conclusão de que formas mais salientes favorecem mais a presença de marcas formais de plural por apresentarem maior diferenciação fônica na relação singular/plural do que as menos salientes ${ }^{5}$ que apresentam menor diferenciação fônica, conforme mostra o Quadro 2.

\begin{tabular}{|l|l|}
\hline Mais saliente & Menos saliente \\
\hline Formação de plural duplo: novo/novos (0,68) & $\begin{array}{l}\text { Nomes regulares oxítonos e monossílabos } \\
\text { tônicos: meu/ meus; pé/pés }(0,38)\end{array}$ \\
\hline Nomes terminado em -L: casal/casais $(0,69)$ & $\begin{array}{l}\text { Regulares proparoxítonos: fábrica/ fábricas } \\
(0,21)\end{array}$ \\
\hline Nomes terminados em -R: cor/cores $(0,65)$ & Regular paroxítono: caro/caros $(0,17)$ \\
\hline
\end{tabular}

Quadro 2- Exemplos da variável 'saliência fônica' e resultados

Scherre (1998) explica esse resultado pelo Princípio da Saliência Fônica, o de que formas mais salientes, por serem mais perceptíveis, são mais retidas.

No que se refere à variável 'relação dos elementos não nucleares em função do núcleo' e 'posição dos elementos nucleares no $\mathrm{SN}^{\text {'6 }}$, Scherre $(1994$, p. 4) chega à conclusão de que elementos não nucleares antepostos são mais marcados $(0,87)$ do que os pospostos $(0,26)$ e também que os núcleos na primeira posição são muito mais marcados $(0,70)$ do que os núcleos de segunda e terceira posição. Além disso, evidencia que os núcleos de segunda e terceira não são igualmente marcados: os da terceira recebem mais marcas $(0,25)$ do que os de segunda posição $(0,21)$.

1) elementos antepostos: novas escola, aquelas cruzinha toda;

2) elementos pospostos: essas estrada nova $\emptyset$, essas besteira toda $\emptyset$;

3) núcleos na primeira posição: coisas lindas;

4) núcleos de segunda posição: essas miséria Ø todinha;

5) núcleos de terceira posição: os outros colégio Ø.

\footnotetext{
5 Resultados da análise 3 que considera processos e tonicidade com uma só variável.

6 Scherre (1988) considera a correlação entre as variáveis classe gramatical e posição como uma melhor forma de interpretar esse fenômeno.
} 
Scherre (1988) explica esse resultado através do Princípio da Iconicidade no que diz respeito ao grau de coesão que se estabelece entre os elementos do SN: quanto maior o grau de coesão mais marcas. Os elementos antepostos, por não permitirem a inserção de elementos entre eles, são mais coesos, portanto, recebem mais marcas, ao passo que os elementos pospostos, por permitirem a inserção de elementos entre eles, são menos coesos, portanto, recebem menos marcas.

No que diz respeito à variável 'formalidade' e ao 'grau dos substantivos e adjetivos', Scherre (1988) chega à conclusão de que itens lexicais informais, assim como substantivos e adjetivos na forma diminutiva/aumentativa favorecem a presença de marcas formais de plural. Isso é explicado pelo fator extralinguístico denominado 'situação de conversação': o uso de itens lexicais e nomes no diminutivo e aumentativo é próprio de situações informais, como é o caso do tipo de coleta realizado para esta pesquisa.

No que se refere à 'animacidade dos referentes', Scherre (1988) mostrou que substantivos marcados positivamente com relação ao traço humano favorecem a presença de marcas formais de plural $(0,55)$, enquanto os substantivos marcados negativamente desfavorecem $(0,44)$. Isso é explicado também pelo Princípio da Saliência, de que formas mais salientes, por serem mais perceptíveis como é o caso do traço [+humano], são mais marcadas.

Quanto à variável 'contexto fonético/fonológico seguinte', a pesquisadora mostrou que quando o fonema seguinte ao item analisado é uma consoante ou pausa há o favorecimento da presença de marcas formais de plural. Em relação à consoante, as que mais favorecem a presença de marcas formais de plural são aquelas com o traço [+surdo] $(0,54)$, [+velar] $(0,56)$ ou [-nasal] $(0,54)$. A não atuação da vogal $(0,49)$ é explicada pelo efeito da dissimilação, principalmente em nomes terminados em $-\mathrm{S}$ : as vezes eu (as vez eu$)$.

No que se refere à 'função resumitiva' que consiste na observação de SNs que funcionam como resumo de ideias anteriores ou não, os resultados, de maneira geral, mostram que há uma tendência de SNs de função resumitiva desfavorecerem a presença de marcas formais de plural $(0,38)$, enquanto os de não função resumitiva a favorecerem $(0,62)$. Esse resultado é explicado pelo princípio da Topicidade ou Baixa Tensão, pois os SNs de função resumitiva, por não serem o ponto de referência do discurso, são menos marcados.

Os resultados das variáveis extralinguísticas controladas por Scherre (1988), por sua vez, mostraram, de maneira geral, que as variáveis 'sexo' e 'escolaridade' exercem influência sobre o fenômeno investigado. As mulheres tenderam mais ao uso da variante 'presença de marcas formais de plural' $(0,58)$ do que os homens $(0,42)$, mostrando, assim, serem mais sensíveis à variante considerada de prestígio. Os informantes mais escolarizados também tenderam mais ao uso da variante "presença de marcas formais de plural' $(0,60)$ do que os menos escolarizados $(0,40)$. Isso é explicado por estarem mais expostos às regras da gramática normativa. A 'idade', por sua vez, apresentou um padrão curvilinear, refletindo, num primeiro momento, uma variação sociolinguística estável.

Um outro trabalho realizado no Brasil sobre a concordância nominal de número foi o de Fernandes (1996), que seguiu, de maneira geral, os mesmos passos metodológicos de Scherre (1988). Fernandes investigou, por sua vez, a fala de 
moradores da Região Sul do Brasil a partir do corpus do projeto $\mathrm{VARSUL}^{7}$ e também de outras regiões do Brasil através de comentários esportivos, entrevistas de televisão e defesas de dissertações de mestrado. A primeira amostra foi constituída de 47 informantes, estratificados de acordo com a etnia (descendentes de açorianos, italianos, alemães e eslavos), sexo, grau de escolaridade (primário, ginásio e colegial) e idade (2549 anos e mais de 50 anos). A segunda amostra foi constituída por 19 informantes cuja estratificação social não foi possível controlar. Foram coletados 5.424 SNs da primeira amostra e 1.521 da segunda amostra. Os dados foram analisados pelo programa computacional VARBRUL.

As variáveis independentes (linguísticas e extralinguísticas) selecionadas pelo programa por ordem de seleção foram: distribuição dos elementos do SN em função de sua posição e de sua relação com o núcleo, níveis de escolarização, marcas precedentes, saliência fônica, idade, etnia, grau dos substantivos e adjetivos, sexo, contexto seguinte e tonicidade dos itens lexicais ${ }^{8}$.

No que se refere às variáveis linguísticas, os resultados de Fernandes (1996) corroboram os resultados de Scherre (1988), pois evidenciam que (i) "elementos não nucleares na primeira $(0,85)$ e segunda posição $(0,72)$ antes do núcleo são muito marcados, com uma queda significativa para os elementos de segunda $(0,32)$ e terceira posição $(0,25)$ pospostos" (p. 49); (ii) marcas levam a marcas e zeros levam a zeros, já que a presença de marcas formais antes do elemento sob análise favorece mais marcas $(0,61)$ e zero formal as desfavorece $(0,10)$; (iii) formas mais perceptíveis são mais marcadas, por exemplo: nomes terminados com formação de plural duplo e terminados em - L favorecem mais a 'presença de marcas formais de plural' $(0,81$ e 0,77$)$. Para a variável 'saliência fônica', assim como Scherre (1988), Fernandes correlaciona processos e tonicidade. Os resultados das duas autoras vão em uma mesma direção, mostrando que elementos linguísticos no grau normal $(0,51)$ apresentam mais marcas formais de plural do que elementos no grau diminutivo/aumentativo $(0,22$, para ambos). Ainda, os resultados das duas autoras mostram que quando o contexto seguinte ao elemento analisado é uma pausa há a tendência de se manter as marcas formais de plural.

Com relação às variáveis extralinguísticas, os resultados de Fernandes (1996) divergem dos de Scherre (1988) no que diz respeito à 'idade', pois mostram que os mais velhos tendem ao uso da 'presença de marcas formais de plural' $(0,55)$, enquanto os mais jovens ao da 'ausência de marcas formais de plural' $(0,45)$. Mas é importante lembrar que Fernandes (1996) controlou apenas duas faixas etárias. Para Scherre (1998) essa variável não foi relevante já que apresentou um padrão curvilinear: tanto os mais jovens quanto os mais velhos apresentam as mesmas probabilidades quanto ao uso da variante 'presença de marcas formais de plural', não indicando, portanto, uma mudança em tempo aparente. Para a variável 'sexo', por sua vez, os resultados de Fernandes convergem para os de Scherre (1988), mostrando que as mulheres tendem um pouco ao uso da variante 'presença de marcas formais de plural' $(0,53)$, enquanto os homens a inibem levemente $(0,46)$.

Campos e Rodrigues em 2002 estudaram também esse mesmo fenômeno observando, dessa vez, a fala de pessoas com nível superior completo ou não. O corpus

www.varsul.org.br

A variável 'características dos itens lexicais' não foi selecionada pelo programa estatístico. 
dessa pesquisa foi proveniente do projeto Norma Urbana Culta (NURC), cujos informantes estão estratificados de acordo com a idade, escolaridade, sexo, origem geográfica (Porto Alegre, Rio de Janeiro, São Paulo, Salvador e Recife) e situação conversacional (elocução formal, EF; diálogo entre dois informantes, D2 e diálogo entre informante e o documentador, DID ${ }^{9}$ ).

De maneira geral, os resultados delas mostraram que os informantes entrevistados utilizam com mais frequência a variante 'presença de marcas formais de plural' (97\%). Para entender a aplicabilidade ou não da regra, as pesquisadoras controlaram além das variáveis extralinguísticas acima citadas, também variáveis linguísticas: saliência fônica, observando processos morfofonológicos de formação de plural, tonicidade dos itens lexicais e número de sílabas; posição do elemento no SN e classe gramatical.

Os resultados das variáveis linguísticas mostraram a inoperância da variável 'saliência' e da variável 'classe gramatical'. Sendo assim, a variável linguística mais relevante foi a 'posição do elemento ocupada no SN': a primeira posição ocupada no $\mathrm{SN}$ é a que aplica mais a regra.

Quanto à 'idade', tanto os informantes da primeira faixa etária quanto os da terceira faixa etária utilizaram de forma categórica a variante 'presença de marcas formais de plural', não se mostrando, assim, uma variável relevante, como na pesquisa de Scherre (1988). Quanto, ao 'sexo', assim como nos estudos acima discutidos, as mulheres tenderam ao uso da variante 'presença de marcas formais de plural'.

Um outro trabalho sobre a variável dependente aqui em estudo é o de Santos que, em 2010 na sua dissertação de mestrado, investigou a fala de moradores da cidade de Pedro Leopoldo (MG). Para essa pesquisa, foram entrevistados 27 informantes, estratificados da seguinte forma: grupo social (classe alta, média e baixa), sexo, idade (17 a 23 anos; 40 a 47 anos; mais de 60 anos) e escolaridade (ensino fundamental, médio e superior, completo ou não). Dessa amostra, foram extraídos 1.297 SNs que foram analisados com o apoio do programa estatístico VARBRUL. De maneira geral, os resultados mostraram que os informantes desse município utilizam com mais frequência a variante 'ausência de marcas formais de plural' (52\%).

No que se refere aos fatores linguísticos controlados (elemento nuclear: posição; elemento não nuclear do SN: classe gramatical; elemento não nuclear do SN: posição; elemento não nuclear do SN: presença/ausência de flexão plural; elemento não nuclear do SN: classe gramatical), apenas dois se mostraram relevantes, que foram 'classe gramatical dos elementos não nucleares do SN' e 'presença/ausência de flexão de marca plural nos elementos não nucleares do SN'. Considerando a correlação entre classe gramatical/posição e relação de anteposição e posposição dos elementos não nucleares em relação ao núcleo, os resultados de Santos corroboraram os de Scherre (1988): elementos não nucleares antepostos ao núcleo do SN são mais marcados do que os elementos não nucleares pospostos. Vale ressaltar que, considerando a variável 'posição' de forma isolada, os resultados de Santos (2010) caminham na direção de uma interpretação funcionalista, já que evidenciam que há uma tendência na língua de se marcar a informação plural somente na primeira posição para se evitar a redundância.

$9 \quad$ Os EFs e DIDs constituem depoimentos de um único informante. 
Quanto aos grupos de fatores extralinguísticos, três foram selecionados: 'sexo', 'escolaridade' e 'grupo social'. Para a primeira variável, os homens mostraram-se favorecedores do uso da variante 'ausência de marcas formais de plural' $(0,66)$, assim como nas pesquisas citadas anteriormente. Para a segunda variável, os informantes de baixa escolaridade tendem a usar mais a variante 'ausência de marcas formais de plural' $(0,70)$.

Sobre a 'faixa etária', que não foi selecionada pelo programa estatístico, esse resultado revela que a concordância nominal de número constitui uma variável estável na fala dos moradores de Pedro Leopoldo (MG).

Conforme pudemos observar a partir da discussão de alguns dos trabalhos realizados sobre a concordância nominal de número no Brasil, esse fenômeno não ocorre de maneira aleatória, há um grupo de fatores linguísticos e extralinguísticos regendo sua sistematicidade. Observemos, no Quadro 3, uma comparação entre a atuação de algumas variáveis independentes sobre a variante 'presença de marcas formais de plural'.

\begin{tabular}{|c|c|c|c|c|c|}
\hline \multicolumn{2}{|c|}{ Variáveis Independentes } & $\begin{array}{l}\text { SCHERRE } \\
(1988)\end{array}$ & $\begin{array}{l}\text { FERNANDE } \\
\text { S (1996) }\end{array}$ & $\begin{array}{l}\text { CAMPOS e } \\
\text { RODRIGUES } \\
(\mathbf{2 0 0 2})\end{array}$ & $\begin{array}{l}\text { SANTOS } \\
(\mathbf{2 0 1 0})\end{array}$ \\
\hline \multirow{4}{*}{$\begin{array}{l}\text { POSIÇÃO NO } \\
\text { SN E CLASSE } \\
\text { GRAMATICAL }\end{array}$} & $\begin{array}{l}\text { Elementos não } \\
\text { nucleares antepostos }\end{array}$ & 0,87 & $\begin{array}{l}0,85 \text { (primeira } \\
\text { posição) } \\
0,72 \text { (segunda } \\
\text { posição) }\end{array}$ & \multirow{4}{*}{$\begin{array}{l}0,94 \text { (primeira } \\
\text { posição) }\end{array}$} & \multirow{2}{*}{$\begin{array}{l}100 \% \\
\text { (primeira } \\
\text { posição) } \\
70 \% \text { (segunda } \\
\text { posição) }\end{array}$} \\
\hline & $\begin{array}{l}\text { Elementos não } \\
\text { nucleares pospostos }\end{array}$ & 0,26 & $\begin{array}{l}0,32 \text { (segunda } \\
\text { posição) } \\
0,25 \text { (terceira } \\
\text { posição) }\end{array}$ & & \\
\hline & $\begin{array}{l}\text { Elementos nucleares } \\
\text { na primeira posição }\end{array}$ & 0,70 & 0,67 & & $100 \%$ \\
\hline & $\begin{array}{l}\text { Elementos nucleares } \\
\text { na segunda posição }\end{array}$ & 0,25 & 0,23 & & $3 \%$ \\
\hline \multirow{5}{*}{$\begin{array}{l}\text { SALIÊNCIA } \\
\text { FÔNICA }\end{array}$} & \multirow{3}{*}{ Mais saliente } & $\begin{array}{l}0,68 \text { (Plural } \\
\text { duplo) }\end{array}$ & $\begin{array}{ll}0,81 & \text { (plural } \\
\text { duplo) } & \end{array}$ & $\begin{array}{l}(0,31) \quad \text { (plural } \\
\text { duplo) }\end{array}$ & \multirow{5}{*}{ não controlado } \\
\hline & & $0,69(-\mathrm{L})$ & $0,77(-\mathrm{L})$ & $(0,67)(-L)$ & \\
\hline & & $0,65(-\mathrm{R})$ & & $(0,67)(-\mathrm{R})$ & \\
\hline & \multirow{2}{*}{ Menos saliente } & $\begin{array}{l}0,38 \\
\text { (oxítonos e } \\
\text { monossílabo } \\
\text { s tônicos) }\end{array}$ & 0,58 & \multirow{2}{*}{$\begin{array}{l}(0,54) \\
\text { (regular) }\end{array}$} & \\
\hline & & $\begin{array}{l}0,21 \\
\text { (regulares } \\
\text { proparoxíton } \\
\text { os) }\end{array}$ & 0,47 & & \\
\hline
\end{tabular}




\begin{tabular}{|c|c|c|c|c|c|}
\hline & & $\begin{array}{l}0,17 \text { (regular } \\
\text { paroxítonos) }\end{array}$ & 0,48 & & \\
\hline \multirow[t]{3}{*}{$\begin{array}{l}\text { CONTEXTO } \\
\text { SEGUINTE }\end{array}$} & Consoante & $\begin{array}{l}0,54 \\
\text { [+surdo] } \\
0,56 \text { [+velar] } \\
0,54 \text { [-nasal] }\end{array}$ & 0,48 & $(0,39)$ & \multirow[t]{3}{*}{ não controlado } \\
\hline & Vogal & 0,49 & 0,51 & $(0,49)$ & \\
\hline & Pausa & 0,57 & 0,56 & $(0,62)$ & \\
\hline \multirow{3}{*}{ IDADE } & $1^{a}$. faixa etária & $\begin{array}{l}0,50 \quad(15-25 \\
\text { anos) }\end{array}$ & $\begin{array}{l}0,45 \text { (25 A } 49 \\
\text { ANOS) }\end{array}$ & knockout & \multirow{3}{*}{$-{ }^{10}$} \\
\hline & $2^{\mathrm{a}}$. faixa etária & $\begin{array}{ll}0,56 \quad(26-49 \\
\text { anos) }\end{array}$ & & $--{ }^{11}$ & \\
\hline & $3^{a}$. faixa etária & $\begin{array}{l}0,49 \quad(50-71 \\
\text { anos) }\end{array}$ & $\begin{array}{l}0,55 \text { (mais de } \\
50 \text { anos) }\end{array}$ & knockout & \\
\hline \multirow{2}{*}{ SEXO } & Homem & 0,42 & 0,46 & 0,84 & 0,34 \\
\hline & Mulher & 0,58 & 0,53 & 0,16 & 0,56 \\
\hline \multirow[b]{2}{*}{$\begin{array}{l}\text { ESCOLARIDA } \\
\text { DE }\end{array}$} & Mais escolarizado & $\begin{array}{l}0,59 \\
\text { (colegial) }\end{array}$ & 0,66 & 97\% (superior) & $\begin{array}{l}0,74 \quad \text { (ensino } \\
\text { superior) }\end{array}$ \\
\hline & Menos escolarizado & $\begin{array}{l}0,50 \\
\text { (ginásio) } \\
0,41 \\
\text { (primário) }\end{array}$ & $\begin{array}{l}0,48 \\
0,32\end{array}$ & $\begin{array}{l}\text { não } \\
\text { controlado }\end{array}$ & $\begin{array}{l}0,30 \\
\text { (fundamental) } \\
0,34 \text { (médio) }\end{array}$ \\
\hline
\end{tabular}

Quadro 3 - Comparação dos resultados de pesquisas sobre a concordância nominal de número, considerando a variante 'presença de marcas formais de plural'

Nesta pesquisa, levantamos as seguintes hipóteses para as variáveis independentes controladas, a partir dos trabalhos acima apresentados:

a) Posição no $\mathrm{SN}$ : elementos linguísticos mais à esquerda tendem a favorecer a presença de marcas formais de plural (SCHERRE, 1988; FERNANDES, 1996; CAMPOS e RODRIGUES, 2002; SANTOS, 2010);

b) Classe gramatical: elementos determinantes tendem a favorecer a presença de marcas formais de plural;

c) Saliência fônica: itens com formação de plural mais salientes tendem a favorecer marcas formais de plural (SCHERRE, 1988; FERNANDES, 1996);

d) Contexto seguinte: a pausa e a consoante tendem a favorecer marcas formais de plural (SCHERRE, 1988; FERNANDES, 1996);

10 A pesquisadora não explicita dados estatísticos dessa variável de forma isolada, já que não foi selecionada pelo programa estatístico.

11 As pesquisadoras não apresentam dados percentuais ou peso relativo para essa faixa etária, já que a variável idade foi descartada pelo programa estatístico. 
e) Idade: tanto os mais jovens quanto os mais velhos tendem a utilizar com a mesma frequência marcas formais de plural (SCHERRE, 1988; CAMPOS e RODRIGUES, 2002; SANTOS, 2010);

f) Sexo: as mulheres tendem ao uso de marcas formais de plural por serem mais sensíveis às variantes de prestígio (SCHERRE, 1988; FERNANDES, 1996; CAMPOS e RODRIGUES, 2002; SANTOS, 2010);

g) Escolaridade: os informantes com maior nível de escolaridade tendem ao uso da presença de marcas formais de plural por estarem expostos por mais tempo à variante de prestígio ensinada nas escolas (SCHERRE, 1988; FERNANDES, 1996; CAMPOS e RODRIGUES, 2002; SANTOS, 2010).

A seguir, discorreremos sobre os pressupostos teórico-metodológicos da Sociolinguística Variacionista e da Dialetologia Pluridimensional, abordagens que, de certa forma, "romperam" com a ideia de homogeneidade da língua em vigor até o século XIX, procurando estudá-la como um fato social, cuja heterogeneidade que a constitui é passível de "ordenação".

\section{A SOCIOLINGUÍSTICA VARIACIONISTA}

O estudo da língua como fato social surge em oposição à linguística estrutural, essencialmente imanentista. Weinreich, Labov e Herzog (2006 [1968]), rompendo com a visão da língua como sistema homogêneo, mostram que as mudanças nas línguas ocorrem sem que isso afete a "comunicação" entre as pessoas. Segundo eles, numa comunidade linguística, um conjunto de variáveis coocorrem e coexistem, podendo levar à mudança com a "morte de uma das variantes" (TARALLO, 2003) ou não, constituindo uma variação estável. Mostram, assim, que nem toda variação leva à mudança, mas toda mudança decorre de variação. Enfim, evidenciam que a variação é inerente ao sistema linguístico e, ainda, que é passível de sistematicidade.

Ainda, criticando Saussure, que separa os estudos sincrônicos de estudos diacrônicos privilegiando os primeiros, Weinreich, Labov e Herzog (2006 [1968]) discutem que a transição de uma determinada forma a outra não se dá por mera substituição, pois o sistema linguístico, como exposto acima, não é homogêneo. O que ocorre, por exemplo, é que uma determinada comunidade A que usa uma forma " $x$ ", ao entrar em contato com uma comunidade B que usa a forma "y", considerada de prestígio, acaba utilizando essa forma junto a sua (x/y) ou acaba reinterpretando a forma de B (x/y'). A mudança, portanto, segundo eles, nunca é substituição, mas é o resultado de um sistema linguístico que estava em variação. Weinreich, Labov e Herzog (2006 [1968]) rompem, dessa forma, as dicotomias saussureanas (langue X parole; sincronia $\mathrm{X}$ diacronia) ao considerarem os fatores sociais agindo sobre a língua e, consequentemente, levando à mudança. Como se observa, é importante levar em consideração no estudo da língua também fatores históricos.

Os estudos de dados de fala realizados por Labov (2008 [1972]) desde a década de 1960 nos Estados Unidos atestam que fatores sociais atuam fortemente sobre determinados fenômenos linguísticos. A partir de seus estudos, o autor consegue oferecer uma teoria e metodologia de coleta e análise de dados empíricos.

Na pesquisa realizada por Labov (2008 [1972]), por exemplo, em Martha's Vineyard, Massachusetts, em 1962, sobre os ditongos /ay/ e /aw/, foi constatado que a 
centralização desses ditongos estava condicionada, principalmente, à idade e à ocupação dos moradores da ilha. Os mais velhos, entre 31 a 45 anos, eram os que mais centralizavam os ditongos, demonstrando, assim, a atitude de pertencimento à ilha, já que valorizavam a pronúncia local. Essa atitude acabava demonstrando a resistência à presença de turistas que utilizavam a variante inovadora (sem centralização). Os pescadores de um lugarejo chamado Chilmark, descendentes de ingleses, foram os que utilizaram com mais frequência a pronúncia centralizada dos ditongos.

Na pesquisa realizada também por Labov (2008 [1972]) em Nova York sobre um outro fenômeno linguístico fonético, o /R/ em coda silábica, foi atestado que a classe social do informante é um dos fatores que estava condicionando o uso dessa variável. No inglês observa-se que o /R/ podia ser realizado com apagamento (pronúncia conservadora) ou sem apagamento (pronúncia inovadora). A pesquisa foi realizada com vendedores de três tipos de lojas. Os empregados da loja de classe média alta (Sacks Fifth Avenue) foram os que mais utilizaram a variante 'presença de /R/', atestando o status de prestígio dessa variante.

Labov (2008 [1972]), em outros trabalhos, também mostrou a importância da escolaridade, formalidade do discurso e sexo, como no estudo da pronúncia do \{-ing\} na fala de adultos nova-iorquinos brancos, cujas variantes são: presença da velar final versus ausência da velar final. Seus resultados atestaram que a velar era mais apagada na fala menos monitorada, o que ele chama de estilo casual, independente da classe social do informante (embora com mais frequência na fala da classe baixa). E as mulheres, na forma monitorada, usam mais a presença da velar (forma menos estigmatizada) que os homens, mostrando que são mais sensíveis que eles ao padrão de prestígio. É importante lembrar que o conservadorismo no uso de uma determinada forma linguística é dependente da organização social de cada comunidade de fala (PAIVA, 2008).

Esses estudos evidenciam, dessa forma, o caráter social da língua que a princípio era vista como uma heterogeneidade desordenada.

\section{A DIALETOLOGIA PLURIDIMENSIONAL}

Ao estudar a concordância nominal de número nesta pesquisa, estamos procurando observá-la levando-se em consideração o fator diazonalidade, que é uma variedade geográfica que conduz à oposição: linguagem urbana versus linguagem rural, muito explorado em trabalhos dialetológicos desde o século XIX. Nesta seção, mostraremos, sucintamente, como surgiu essa abordagem e a evolução de seu método de pesquisa ao adotar fatores controlados pela Sociolinguística Variacionista.

A Dialetologia é um ramo da Linguística que surge no final do século XIX e tem como método, por excelência, a Geografia Linguística ou Geolinguística para um melhor conhecimento da diversidade linguística de um país, uma região. O referido método foi difundido por Jules Gilliéron, entre 1902 a 1910, com a publicação do Atlas Linguístico da França (ALF), considerado o marco dos estudos dialetais. Esse método permite uma visão ampla de um dado fenômeno linguístico, pois, através da utilização de mapas, distribui espacialmente os fenômenos linguísticos da área estudada, como a pronúncia e os meios de expressão de que uma determinada comunidade dispõe. A Geolinguística constitui-se em um dos métodos mais significativos para o registro e análise da variedade linguística, sobretudo na Europa e nas Américas, como confirmam 
não só os inúmeros atlas linguísticos regionais e nacionais já publicados que abrangem família de línguas - como o Atlas Linguístico Roman (ALIR) - ou um conjunto de países - como o Atlas Linguarum Europae (ALE).

No Brasil, o desenvolvimento de estudos dialetológicos deve-se, principalmente, a Amadeu Amaral, Antenor Nascentes, Mário Marroquim, Serafim da Silva Neto e Celso Cunha. Segundo Nascentes (apud CRUZ, 2004), os estudos dialetais, no Brasil, são divididos em duas fases: a primeira tem como marco inicial o ano de 1826 e a segunda o ano de 1920, com a publicação, respectivamente, de um estudo realizado por Borges de Barros e O Dialeto Caipira, de Amadeu Amaral. Cardoso e Ferreira (1994) acrescentam uma terceira fase: a que se inicia no ano de 1952 com o objetivo de elaborar o Atlas Linguístico do Brasil (Comissão de Filologia da Casa de Rui Barbosa). A partir desse ano, a Geografia Linguística avança, acabando por redundar no primeiro atlas linguístico regional do país, o Atlas Prévio dos Falares Baianos (APFB), coordenado por Nelson Rossi e publicado em 1963. Mota e Cardoso (2005), por sua vez, propõem uma quarta fase que é marcada pela retomada em 1996 do projeto do Atlas Linguístico do Brasil. Essa etapa é caracterizada pelo aumento da elaboração de Atlas Linguísticos regionais que já incorporaram na sua metodologia princípios da Sociolinguística, como o controle sistemático de grupos de fatores sociais, como idade, escolaridade, sexo etc. Ainda, essa nova fase incorpora preocupações de outras ciências, como da Etnolinguística.

Essa nova fase dos estudos dialetológicos no Brasil é conhecida como Dialetologia Pluridimensional já que as pesquisas passam a abandonar a visão monodimensional da coleta de dados da Dialetologia Tradicional.

Thun (1998) discute que a Dialetologia tradicional (areal), por ser monodimensional, constitui uma sociolinguística limitada, pois considerava em seus trabalhos apenas um tipo de informante: homem mais velho, de nível cultural baixo, de zona rural, com restrito movimento no espaço e poucos contatos. Por outro lado, para ele a Sociolinguística tradicional, por não trabalhar com a diatopia, constitui uma sociolinguística limitada. Segundo Thun (1998), sem arealização não se pode reconstituir analiticamente o espaço variacional. Observando isso, os dialetólogos passaram a "dialetalizar" a sociolinguística, surgindo assim a Dialetologia Pluridimensional, que trata de uma abordagem da variação linguística e das relações entre variantes e variedade por um lado e falantes por outro.

Para a dimensão diazonalidade, levantamos a hipótese de que informantes moradores da região central, que consideramos uma região mais urbana por ser mais desenvolvida, apresentem maior probabilidade de uso da variante 'presença de marcas formais de plural', variante mais prestigiada, enquanto os informantes da Costa da Lagoa, que consideramos uma região menos urbana por ser mais isolada e menos sujeita à influência externa, tendam a apresentar maior probabilidade de uso da variante 'ausência de marcas formais de plural'.

\section{RESULTADOS}

Nesta pesquisa foram analisados 1.357 dados provenientes dos SNs encontrados nas entrevistas investigadas. Desses dados, 1.029 foram da variante 'presença de marcas formais de plural', correspondendo a $75 \%$ dos dados, e 328 foram da variante 'ausência 
de marcas formais de plural', correspondendo a $24 \%$ dos dados, conforme ilustrado no Gráfico 1.

Gráfico 1- Distribuição geral da variável ‘concordância nominal de número’ em Florianópolis

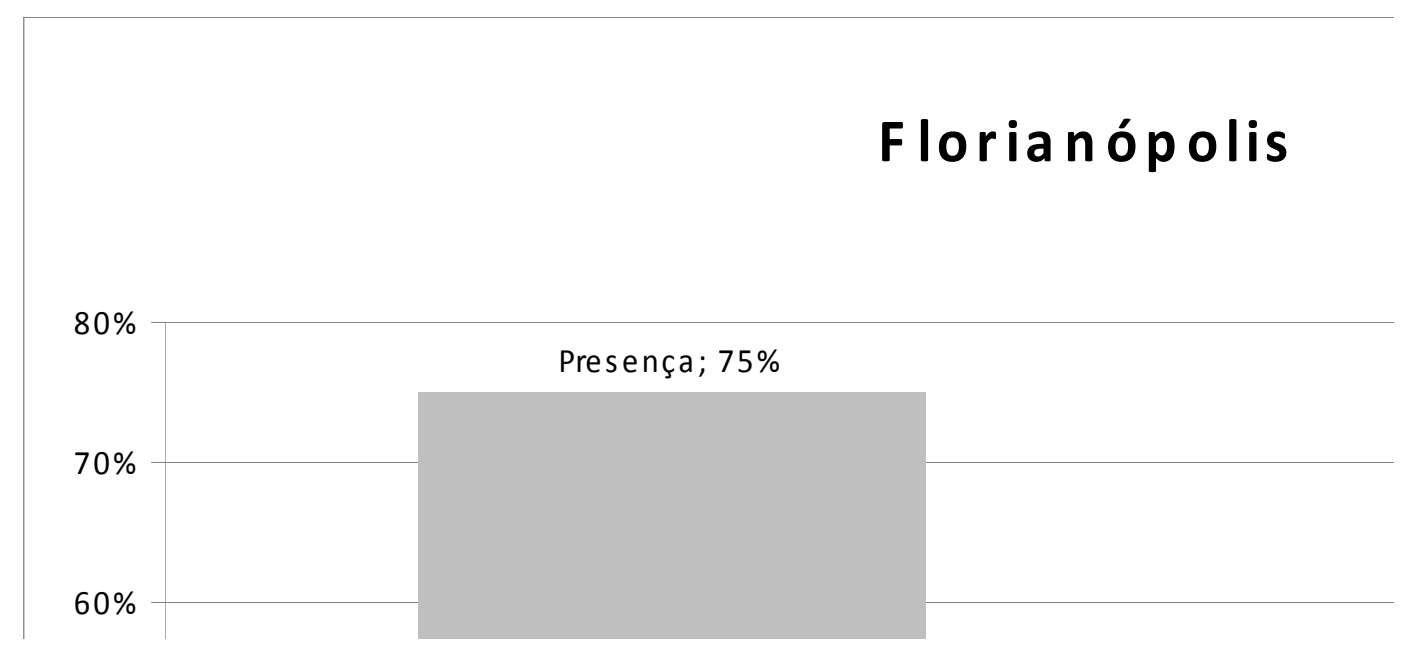

Como observamos, os informantes de Florianópolis entrevistados utilizam com mais frequência a variante 'presença de marcas formais de plural'.

\subsection{Variáveis independentes selecionadas: linguísticas e extralinguísticas}

Das variáveis independentes controladas nesta pesquisa, o programa Goldvarb 2001 selecionou as seguintes, por ordem de relevância: 'classe gramatical', 'escolaridade', 'idade', 'saliência fônica', 'diazonalidade' e 'posição'. Discutiremos a seguir os resultados encontrados para essas variáveis. Primeiramente, apresentaremos as linguísticas e, em seguida, as extralinguísticas.

\subsubsection{Variáveis linguísticas selecionadas}

\subsubsection{Classe Gramatical}

No que diz respeito à 'classe gramatical', nossa hipótese era a de que elementos determinantes favorecessem a presença de marcas formais de plural, assim como aconteceu na amostra de Scherre (1988) e Fernandes (1996), considerando a variável sem nenhuma correlação com outra. Nos nossos dados encontramos o resultado exposto na Tabela 1 . 
Tabela 1- Frequência e probabilidade da variante 'presença de marcas formais de plural', segundo a variável 'classe gramatical'

\begin{tabular}{l|l|l|l}
\hline Classe gramatical & Aplicação/total & $\%$ & P.R. \\
\hline Determinante & $389 / 395$ & $98 \%$ & 0,90 \\
\hline Pronome Possessivo & $56 / 58$ & $96 \%$ & 0,81 \\
\hline Pronome indefinido & $49 / 51$ & $96 \%$ & 0,79 \\
\hline Advérbio & $6 / 7$ & $85 \%$ & 0,50 \\
\hline Substantivo & $409 / 636$ & $64 \%$ & 0,25 \\
\hline Adjetivo & $33 / 48$ & $68 \%$ & 0,22 \\
\hline Numeral & $87 / 162$ & $53 \%$ & 0,12 \\
\hline
\end{tabular}

Como observamos nos resultados numéricos, nossa hipótese é atestada, uma vez que, realmente, elementos determinantes $(0,90)$, além dos pronomes possessivos $(0,81)$ e indefinidos $(0,79)$ são os que mais condicionam a 'presença de marcas formais de plural'. Essa variável foi a que se mostrou mais significativa dentre as controladas, pois foi selecionada em primeiro lugar pelo programa estatístico utilizado. A seguir alguns exemplos de nossa amostra. As classes gramaticais são ilustradas em itálico.

\begin{tabular}{|l|l|}
\hline Classe & Exemplos \\
\hline Determinantes & $\begin{array}{l}\text { "dessas reclamações é" (CENT-2MB) }{ }^{12} \text {, "os boneco de } \\
\text { barro" (CENT-2BF) }\end{array}$ \\
\hline Substantivo & "as pessoa" (TR-2AF) \\
\hline Pronome Possessivo & "dos meus passeios..." (CENT-2BF) \\
\hline Numeral & "três homens" (CENT-1BM) \\
\hline Pronome indefinido & "várias áreas pra" (CO-1BF) \\
\hline Adjetivo & "excelentes neto" (CENT-2BF) \\
\hline Advérbio & $\begin{array}{l}\text { "dos balneários mais bonitos daqui" (TR-2MB); } \\
\text { "algumas aulas mais diferenciadas né" (COQ-1MA) }\end{array}$ \\
\hline
\end{tabular}

Quadro 4- Exemplos de classe gramatical dos elementos do SN

\subsubsection{Saliência Fônica}

12 Para CENT: Região Central; Para TR lê-se Trindade; Para COQ: Coqueiros; Para CO: Costa da Lagoa; Para 1: informante entre 15 a 37 anos; Para 2: informante com mais de 40 anos; Para A: menos escolarizado; Para B: mais escolarizado; Para F: informante mulher; Para M: informante homem. 
No que se refere à 'saliência fônica', levantamos a hipótese de que itens com formação de plural mais saliente tenderiam a favorecer marcas formais de plural, assim como foi encontrado na amostra de Scherre (1988) e Fernandes (1996).

Tabela 2- Frequência e probabilidade da variante 'presença de marcas formais de plural', segundo a variável 'saliência fônica'

\begin{tabular}{l|l|l|l}
\hline Saliência Fônica & Aplicação/total & \% & P.R. \\
\hline Mais saliente & $66 / 77$ & $85 \%$ & 0,78 \\
\hline Menos saliente & $963 / 1280$ & $75 \%$ & 0,40 \\
\hline
\end{tabular}

Como observamos na Tabela 2, nomes terminados com formação de plural mais saliente apresentam uma maior probabilidade de reterem as marcas formais de plural, já que apresentam um material fônico na oposição singular/plural mais perceptível, como ilustrado em itálico nos exemplos abaixo:

\begin{tabular}{|l|l|}
\hline Saliência Fônica & Exemplos \\
\hline Mais saliente & $\begin{array}{l}\text { "dois rapazes" (TR-2FB), "aquelas tradições deles né” (CO-2FB), } \\
\text { "todos os lugares assim” (1FA); “os macacões” (COQ-2FB) }\end{array}$ \\
\hline Menos saliente & "as guria" (CO-2MA); “as tias não" (COQ-2FB) \\
\hline \multicolumn{1}{|l}{ Quadro 5- Exemplos da variável “saliência fônica’ }
\end{tabular}

\subsubsection{Posição}

No que se refere à 'posição', nossa hipótese era a de que elementos linguísticos mais à esquerda tendessem a favorecer a presença de marcas formais de plural. Esse resultado foi constatado na pesquisa de Scherre (1988), de Fernandes (1996), de Campos e Rodrigues (2002) e de Santos (2010). Nossos resultados são apresentados na Tabela 3.

Tabela 3- Frequência e probabilidade da variante 'presença de marcas formais de plural', segundo a variável 'posição'

\begin{tabular}{l|l|l|l}
\hline Posição & Aplicação/total & $\mathbf{\%}$ & P.R. \\
\hline Primeira & $559 / 637$ & $87 \%$ & .57 \\
\hline Segunda & $403 / 635$ & $63 \%$ & .41 \\
\hline Terceira & $62 / 78$ & $79 \%$ & .59 \\
\hline Quarta & $5 / 7$ & $71 \%$ & .49 \\
\hline
\end{tabular}

Como vemos, atestamos nossa hipótese em termos percentuais, tendo em vista que elementos que ocupam a primeira posição, ou seja, mais à esquerda do SN são os que tendem a ser mais marcados $(87 \%)$, porém observamos ainda que os que ocupam a terceira posição também favorecem a presença de marcas formais de plural no que diz 
respeito ao peso relativo $(0,59)$. Ressaltamos que essa variável foi selecionada em último lugar dentre as aqui controladas, ao contrário das outras pesquisas.

\begin{tabular}{|l|l|}
\hline Posições & Exemplos \\
\hline Primeira Posição & “uns problema de família” (TR-2AF) \\
\hline Segunda Posição & "os caraØ que” (TR-1AF) \\
\hline Terceira Posição & “das outras pessoas" (TR-2BF), "as duas coisas assim” (TR-2BF). \\
\hline Quarta Posição & "algumas aulas mais diferenciadas né” (COQ-1AM) \\
\hline
\end{tabular}

Quadro 6- Exemplos de posição linear do elemento no SN

Para compreendermos melhor esse resultado, cruzamos a variável 'classe gramatical' com a variável 'posição' e obtivemos o que segue na Tabela 4.

Tabela 4- Frequência da variante 'presença de marcas formais de plural', segundo as variáveis 'classe gramatical' e 'posição'

\begin{tabular}{|c|c|c|c|c|c|c|c|}
\hline 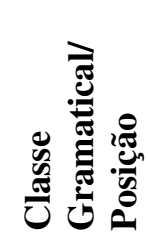 & 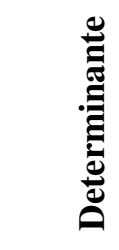 & 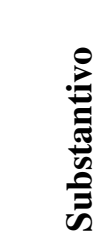 & 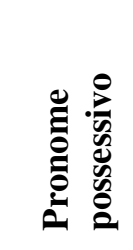 & 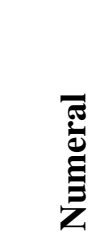 & 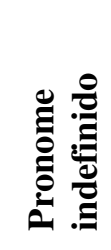 & 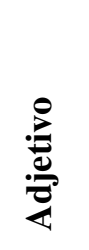 & 竞 \\
\hline 1 & $98 \%$ & $96 \%$ & $97 \%$ & $50 \%$ & $98 \%$ & $86 \%$ & $0 \%$ \\
\hline 2 & $100 \%$ & $60 \%$ & $95 \%$ & $72 \%$ & $100 \%$ & $88 \%$ & $67 \%$ \\
\hline 3 & $100 \%$ & $90 \%$ & $100 \%$ & $0 \%$ & $50 \%$ & $41 \%$ & $100 \%$ \\
\hline 4 & $0 \%$ & $0 \%$ & $0 \%$ & $0 \%$ & $0 \%$ & $71 \%$ & $0 \%$ \\
\hline
\end{tabular}

O que observamos na Tabela 4, é que elementos não nucleares, no caso determinantes e pronomes indefinidos, tendem a apresentar mais a 'presença de marcas formais de plural' quando estão na primeira posição em relação às demais classes na mesma posição. Mas também eles são bem marcados quando estão na segunda e na terceira posição. Observamos também que o substantivo é muito mais marcado na primeira posição e, em seguida, na terceira posição. Esse resultado vai ao encontro de uma visão funcionalista da língua, a de que há uma tendência de reter a informação na primeira posição por uma questão de economia.

Scherre (1997) encontra esse mesmo resultado e tenta explicá-lo em função de duas outras variáveis que não foi possível analisar nesta pesquisa: a 'coesão sintagmática', no plano sintagmático, e a 'configuração sintagmática', no plano oracional. No que se refere à 'coesão', a pesquisadora mostra que os elementos não nucleares antepostos ao núcleo são muito mais marcados do que os pospostos por estabelecerem uma relação mais coesa entre si, pois aceitam menos inserção de elementos linguísticos do que os pospostos (menos coesos, portanto). 
No que se refere à 'configuração sintagmática' do SN, Scherre $(1988,1997)$ evidencia que estruturas que apresentem um artigo definido ou um quantificador todo, na primeira posição do $\mathrm{SN}$, e a presença de substantivo, na última posição do $\mathrm{SN}$, "são duas forças poderosas no sentido de provocarem a presença de todas as variantes explícitas de plural em todos os elementos flexionáveis do SN" (p. 188). Como neste artigo, nos propomos a fazer apenas uma análise atomística, não conseguimos ver essa variável estatisticamente, mas abaixo ilustramos alguns exemplos de SNs, cuja estrutura elucidada por Scherre $(1988,1997)$, pode explicar o resultado da correlação entre posição e classe gramatical.

\begin{tabular}{|l|l|}
\hline Configuração sintagmática & Exemplos \\
\hline Artigo ... substantivo & $\begin{array}{l}\text { "os meus feijōes" (TRI-2BF), “os três } \\
\text { filhos... não" (TRI-2BF), "as duas } \\
\text { faculdades...” (COQ-1BM) }\end{array}$ \\
\hline Quantificador (todo) ... substantivo & "todos os países" (TRI-2BF) \\
\hline
\end{tabular}

Quadro 7- Exemplos da configuração sintagmática nos dados de Florianópolis

\subsubsection{Variáveis extralinguísticas selecionadas}

\subsubsection{Escolaridade}

No que se refere à 'escolaridade', nossa hipótese era a de que informantes com maior nível de escolaridade tenderiam ao uso da variante 'presença de marcas formais de plural', assim como foi encontrado nas amostras de Scherre (1988), Fernandes (1996), Campos e Rodrigues (2002), Santos (2010). Nossos resultados são apresentados na Tabela 5 .

Tabela 5- Frequência e probabilidade da variante 'presença de marcas formais de plural', segundo a variável 'escolaridade'

\begin{tabular}{l|l|l|l}
\hline Escolaridade & Aplicação/total & $\%$ & P.R. \\
\hline Ensino Superior & $666 / 811$ & $82 \%$ & 0,61 \\
\hline Ensino Fundamental & $363 / 546$ & $66 \%$ & 0,33 \\
\hline
\end{tabular}

Conforme ilustrado na tabela, nossa hipótese é atestada, tendo em vista que são os informantes com maior nível de escolaridade que tendem ao uso da variante 'presença de marcas formais de plural' $(0,61)$. Isso acontece possivelmente por eles estarem expostos por mais tempo a essa variante que, por sua vez, é prestigiada socialmente.

\subsubsection{Idade}

No que se refere à 'idade', nossa hipótese era a de que tanto os informantes mais jovens quanto os mais velhos tendiam a utilizar com a mesma frequência marcas 
formais de plural (SCHERRE, 1988; CAMPOS e RODRIGUES, 2002; SANTOS, 2010). Nossos resultados atestaram o que segue na Tabela 6.

Tabela 6- Frequência e probabilidade da variante 'presença de marcas formais de plural', segundo a variável 'idade'

\begin{tabular}{l|l|l|l}
\hline Idade & Aplicação/total & $\%$ & P.R. \\
\hline $\begin{array}{l}\text { Jovem (menos de 37 } \\
\text { anos) }\end{array}$ & $526 / 658$ & $79 \%$ & 0,60 \\
\hline $\begin{array}{l}\text { Velho (mais de 40 } \\
\text { anos) }\end{array}$ & $503 / 699$ & $71 \%$ & 0,40 \\
\hline
\end{tabular}

Como observamos, nossa hipótese não é atestada, uma vez que os informantes mais jovens são os que utilizam com mais frequência a variante "presença de marcas formais de plural' $(0,60)$.

Nos resultados de Scherre (1988), Campos e Rodrigues (2002) e Santos (2010) essa variável não é selecionada como estatisticamente relevante, pois os mais velhos e os mais jovens mostraram apresentar o mesmo comportamento no uso da variável aqui em estudo. Ressaltamos que essas pesquisadoras controlaram três faixas etárias. Nesta pesquisa, diferentemente, a variável 'idade' se mostrou relevante, uma vez que dentre as variáveis controladas, essa variável foi selecionada em terceiro lugar.

É importante lembrar que nos resultados de Fernandes na pesquisa realizada com informantes de Santa Catarina em 1996 foram os mais velhos que utilizaram $(0,55)$ mais essa variante, enquanto os mais jovens aplicaram menos a regra $(0,45)$. É importante lembrar que a referida pesquisadora trabalhou apenas com duas faixas etárias, assim como é feito nesta pesquisa.

Os resultados desta pesquisa poderiam nos levar a pensar numa possível mudança, em tempo aparente, já que quem está utilizando mais a variante 'presença de marcas formais de plural' em Florianópolis são os mais jovens, em detrimento dos mais velhos, considerando duas faixas etárias. No entanto, pensamos que pode haver uma outra variável atuando por trás desse fenômeno, como o mercado de trabalho, variável controlada por Scherre (1988) e que mostrou que os informantes que estão inseridos no mercado de trabalho, cuja ocupação exija o uso de formas de maior prestígio, tendem ao uso da variante 'presença de marcas formais de plural'. Nesta pesquisa, porém, não foi controlada essa variável.

\subsubsection{Diazonalidade}

No que se refere à 'diazonalidade', nossa hipótese era a de que informantes moradores da região considerada mais urbana, região central, apresentariam maior probabilidade de uso da variante 'presença de marcas formais de plural', enquanto informantes moradores da região considerada menos urbana, Costa da Lagoa, apresentariam maior probabilidade de uso da variante 'ausência de marcas formais de plural'. Nossos resultados são evidenciados na Tabela 7. 
Tabela 7- Frequência e probabilidade da variante 'presença de marcas formais de plural', segundo a variável 'diazonalidade'

\begin{tabular}{l|l|l|l}
\hline Diazonalidade & Aplicação/total & \% & P.R. \\
\hline Mais urbano & $497 / 624$ & $79 \%$ & 0,57 \\
\hline Menos urbano & $532 / 733$ & $72 \%$ & 0,43 \\
\hline
\end{tabular}

Como observamos na tabela, atestamos nossa hipótese, uma vez que são os informantes da região considerada mais urbana (Trindade e Coqueiros) que apresentam a maior probabilidade do uso da variante 'presença de marcas formais de plural'. Isso pode ser explicado por se tratar de uma região mais "desenvolvida" que exige dos informantes o uso de uma variante mais prestigiada socialmente, como é o caso da presença de marcas em todos os elementos flexionáveis do SN.

No caso da região considerada menos urbana, Costa da Lagoa, o não favorecimento do uso dessa variante pode ser explicado por ser uma região que não sofre tantas influências externas, aparentemente, portanto, sem muita "preocupação" em fazer uso de variantes consideradas de prestígio. É uma região cujos moradores parecem não ter tanto contato com outros bairros por ser um bairro mais isolado cujo acesso se dá exclusivamente por meio de barcos e por trilha.

Vale ressaltar aqui, ainda, os resultados de outras pesquisas realizadas na Costa da Lagoa que mostram que mesmo sendo uma comunidade mais isolada, ainda assim os moradores fazem uso de variantes usadas com mais frequência em áreas consideradas urbanas. Como é o caso de nossa pesquisa também, já que os moradores apresentaram uma frequência de uso de $72 \%$ da variante 'presença de marcas formais de plural', considerada de mais prestígio. Mascarello (2010), por exemplo, ao estudar a variação na concordância verbal de terceira pessoa do plural também na Costa da Lagoa mostrou que os informantes dessa comunidade utilizam, de certa forma, com mais frequência a variante mais prestigiada (concordância marcada), correspondendo a $68 \%$ dos dados, principalmente os moradores mais escolarizados e mais jovens.

Dessa forma, observamos os moradores da região menos urbana "incorporando" variantes de uma comunidade mais urbana em sua fala, dependendo do grau de mobilidade de seus falantes: se saem ou não com frequência de sua comunidade. Uma variável que poderá ser explorada em pesquisas futuras a fim de explicar melhor os resultados aqui encontrados.

\section{CONSIDERAÇÕES FINAIS}

Através desta pesquisa pudemos observar como é realizada a concordância nominal de número na fala de moradores de duas regiões de Florianópolis (SC), assim como observarmos a sistematicidade que rege essa variação.

Quanto ao resultado geral, vimos que os moradores florianopolitanos entrevistados caracterizam seu falar pelo uso com maior frequência da variante 'presença de marcas formais de plural' (75\%). Quanto à análise dos grupos de fatores independentes, vimos que, dos linguísticos, a variante 'presença de marcas formais de plural' é condicionada pela classe gramatical do elemento linguístico, pela saliência fônica e pela posição ocupada no SN. Dos extralinguísticos, vimos que a variante 
'presença de marcas formais de plural' é condicionada pela escolaridade dos informantes, pela idade deles e pelo bairro em que moram. Resultados que, de maneira geral, corroboram os de outras pesquisas.

Ainda, atestamos que a variável dependente em estudo não é condicionada de certa forma, pelo sexo e pelo contexto fonético/fonológico seguinte, já que foram variáveis que não foram selecionadas pelo programa estatístico utilizado. O que chama a atenção é que em outras pesquisas a variável 'sexo' é selecionada, embora a diferença de uso da variante 'presença de marcas formais de plural' entre homem e mulher não seja tão significativa. $\mathrm{O}$ que se observa são mulheres sendo mais sensíveis à variante de prestígio do que os homens. Tendência também atestada em trabalhos de outra natureza.

Esperamos, enfim, com esta pesquisa ter contribuído para o conhecimento de mais uma variedade do português brasileiro ao estudar a concordância nominal de número, mostrando que por trás desse fenômeno há fatores sociais e linguísticos atuando.

\section{REFERÊNCIAS}

CAMPOS, O. G. L. de S.; RODRIGUES, A. C. S. Flexão Nominal: indicação de pluralidade no sintagma nominal. In: ILARI, R. (org.). Gramática do português falado. Volume II: níveis de análise linguística. $4^{\mathrm{a}}$ ed. Campinas (SP): editora da UNICAMP, 2002, p. 101-102.

CARDOSO, S.; FERREIRA, C. A dialetologia no Brasil. São Paulo: Contexto, 1994.

CRUZ, M. L. de C. Atlas Lingüístico do Amazonas - ALAM. Rio de Janeiro: UFRJ, 2 sem. 2004. Tese de Doutorado em Letras Vernáculas.

FERNANDES, M. Concordância nominal na região sul. Florianópolis: UFSC, dissertação de mestrado, 1996.

LABOV, W. Padrões Sociolinguísticos. Tradução: Marcos Bagno, Maria Marta Pereira Scherre, Caroline Rodrigues Cardoso. São Paulo: Parábola, 2008.

MASCARELLO, L. J. Variação na concordância verbal de terceira pessoa do plural na fala dos florianopolitanos nativos da Costa da Lagoa. Working Paper em Linguística, 57-68 (n. esp.), 2010.

MONGUILHOTT, I. de O. e S. Estudo sincrônico e diacrônico da concordância verbal de terceira pessoa do plural no $P B$ e no PE. Florianópolis: UFSC, doutorado em Linguística, 2009.

MOTA, J. A.; CARDOSO, S. A. M. Comunicação apresentada, em primeira versão, no IV Congresso Internacional da ABRALIN (Brasília, 17 a 19 de fevereiro de 2005), integrante da mesa-redonda Os estudos dialetais brasileiros: percursos historiográficos.

NARO, A.; SCHERRE, M. M. P A. Sobre a concordância de número no português falado do Brasil. In Ruffino, Giovanni (org.) Dialettologia, geolinguistica, sociolinguistica.(Atti del XXI Congresso Internazionale di Linguistica e Filologia Romanza) Centro di Studi Filologici e Linguistici Siciliani, Universitá di Palermo. Tübingen: Max Niemeyer Verlag, 5:509-523, 1998. 
PAIVA, M. da C. de. A variável gênero/sexo. IN: MOLLICA, M. C.; BRAGA, M. L. (Orgs). Introdução à Sociolinguística: o tratamento da variação. São Paulo: Contexto, 2008.

PRETI, D. (org.). Análise de Textos Orais. São Paulo: FFLCH, 1993.

SANTOS, L. S. M. Sobre a ausência de concordância nominal no português falado em Pedro Leopoldo-MG: uma abordagem variacionista. Belo Horizonte: UFMG. Dissertação de mestrado, 2010.

SCHERRE, M. M. P. Reanálise da concordância nominal em português, Rio de Janeiro: UFRJ. Tese de Doutorado, 1988.

Aspectos da concordância de número no português do Brasil. Revista Internacional de Língua Portuguesa (RILP): Norma e variação do português. Associação das Universidades de Língua Portuguesa, dez, 1994. 206, 1997.

Concordância nominal e funcionalismo. ALFA. São Paulo, 41 (n.esp), 181-

SPESSATTO, M. B. Formas linguísticas inovadoras não conhecem fronteiras: nós/ a gente na fala da população da Costa da Lagoa. Working Paper em Linguística, 82-93 (n. esp.), 2010.

TARALlO, F. A Pesquisa Sociolinguística. 7. ed. São Paulo: Ática, 2003.

WEINREICH, U.; LABOV, W.; HERZOG, M. Fundamentos empíricos para uma teoria da mudança linguística. Trad. de Marcos Bagno. São Paulo: Parábola editorial, 2006 [1968].

Data de submissão: 28/05/2013

Data de aceite: 19/10/2013 
ANEXO

\section{Normas para Transcrição Grafemática}

\begin{tabular}{|c|c|c|}
\hline Ocorrências & Sinais & Exemplificação \\
\hline $\begin{array}{l}\text { Incompreensão de palavras ou } \\
\text { segmentos }\end{array}$ & $(\quad)$ & $\begin{array}{l}\text { do nível da renda... ( ) nível de renda } \\
\text { nacional. }\end{array}$ \\
\hline Hipótese do que se ouviu & (hipótese) & 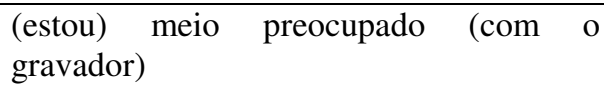 \\
\hline $\begin{array}{lr}\text { Truncamento } & \text { (havendo } \\
\text { homografia, usa-se acento } \\
\text { indicativo da tônica e/ou timbre) }\end{array}$ & / & e comé/ e reinicia \\
\hline Entonação enfática & maiúscula & porque as pessoas reTÊM moeda \\
\hline $\begin{array}{l}\text { Prolongamento de vogal e } \\
\text { consoante (como s, r) }\end{array}$ & $\begin{array}{l}:: \quad \text { podendo } \\
\text { aumentar }:::: \text { ou } \\
\text { mais }\end{array}$ & ao emprestarem os... éh::..... o dinheiro... \\
\hline Silabação & - & por motivo tran-sa-ção \\
\hline Interrogação & $?$ & e o Banco... Central... certo? \\
\hline Qualquer pausa & $\ldots$ & $\begin{array}{l}\text { são três motivos... ou três razões... que } \\
\text { fazem com que se retenha moeda... existe } \\
\text { uma... retenção }\end{array}$ \\
\hline $\begin{array}{l}\text { Comentários descritivos do } \\
\text { transcritor }\end{array}$ & ((minúscula)) & $(($ tossiu $))$ \\
\hline $\begin{array}{l}\text { Comentários que quebram a } \\
\text { seqüência temática da exposição; } \\
\text { desvio temático. }\end{array}$ & -- -- & $\begin{array}{l}\text {... a demanda de moeda -- vamos dar essa } \\
\text { notação -- demanda de moeda por motivo }\end{array}$ \\
\hline $\begin{array}{l}\text { Superposição, simultaneadade de } \\
\text { vozes }\end{array}$ & $\begin{array}{l}\text { Ligando as } \\
\text { tinhas }\end{array}$ & 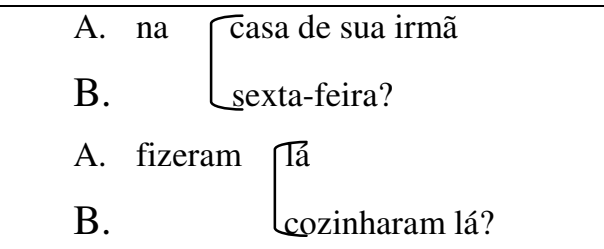 \\
\hline $\begin{array}{l}\text { Indicação de que a fala foi } \\
\text { tomada ou interrompida em } \\
\text { determinado ponto. Não no seu } \\
\text { início, por exemplo. }\end{array}$ & $(\ldots)$ & (...) nós vimos que existem... \\
\hline $\begin{array}{l}\text { Citações literais ou leituras de } \\
\text { textos, durante a gravação. }\end{array}$ & “" & $\begin{array}{l}\text { Pedro Lima... ah escreve na ocasião... "O } \\
\text { cinema falado em língua estrangeira não } \\
\text { precisa de nenhuma baRREira entre } \\
\text { nós"... }\end{array}$ \\
\hline
\end{tabular}

